\title{
Peran Orientasi Kewirausahaan Dalam Mendukung Teknologi Bersih
}

Author: Deneq Egi Anjani Putri (Fakultas Bisnis dan Ekonomika, Universitas Surabaya)

\section{Pengantar}

Adopsi teknologi bersih tidak bisa dipisahkan dari inisiatif perusahaan dalam mengadopsi orientasi kewirausahaan, yang merupakan perilaku perusahaan dalam berinovasi maupun keberanian mengambil risiko (Pratono, Darmasetiawan, Yudiarso, \& Jeong, 2019). Orientasi kewirausahaan adalah kegiatan yang unik, terlihat dari inovasi dalam mengembangkan perusahaan sehingga membutuhkan owner yang cermat dan responsif serta pengalaman bekerja (Altinay \& Wang, 2011). Hal tersebut muncul dari kreativitas karyawan yang memungkinkan perusahaan bukan hanya mampu berinovasi tetapi juga berani mengambil risiko dan bersikap proaktif seperti dalam konsep EO (Awwad \& Ali, 2012). Fenomena tersebut bisa terjadi dengan adaanya pimpinan yang mempunyai pengalaman kerja, keterampilan, berkompetisi dalam bekerja, dan mempunyai latar belakang pendidikan formal yang cukup (Altinay \& Wang, 2011).

Dilihat dari segi mental karyawan dan wirausawan, kondisi emosional kerap dijumpai dalam pengambilan risiko di perusahaan. Faktor emosional yang tidak dikendalikan akan berdampak buruk dalam pengambilan risiko (Aydemir \& Aren, 2017). Sehingga pendidikan secara finansial dapat menghilangkan kemungkinan mengangambil risiko yang tidak tepat. Tidak hanya itu saja, faktor usia juga berpengaruh dalam pengambilan risiko ke tingkat yang lebih besar (Moschilla, Tomkins, \& Simmons, 2018). Ketidakmampuan dalam pengambilan risiko yaitu dapat menyebabkan bisnis jatuh (McCarthy, 2000). Akan tetapi pengambilan risiko tersebut juga berdampak positif dengan adanya kontribusi dalam krisis perusahaan. Agar hasil dari pengambilan keputusan tidak merugi maka perusahaan harus menggunakan stategi yang melibatkan kerja sama dengan banyak orang atau tim (Ratliff \& Hanks, 1992). Pengalaman dari wirausahawan juga penting. Karena hal tersebut yang membuat wirausahawan belajar bahwa sesuatu yang dicapai membutuhkan kerja keras dan biaya yang besar (McCarthy, 2000).

Artikel ini bertujuan untuk mengulas literature tentang perilaku perusahaan dalam mengadopsi teknologi bersih. Beberapa konsep yang dibahas dalam literature ini meliputi 
konsep teknologi bersih serta perilaku keberanian mengambil risiko dalam konteks orientasi kewirausahaan, Output penelitian ini berupa preposisi yang dikembangkan dari kajian literature. Tulisan ini merupakan penelitian awal yang akan ditindaklanjuti dengan kajian empiris.

\section{Kinerja Perusahaan}

Dalam literature ekonomi klasik, perusahaan diasumsikan mempunyai tujuan mencapai profit. Dalam perkembangannya, kinerja perusahaan merupakan prestasi yang ada dalam perusahaan ketika perusahaan dapat memanfaatkan sumber daya dan keterampilan dalam meningkatkan kualitas perusahaan (Calantone, Cavusgil, \& Zhao, 2002). Tingginya kinerja perusahaan didukung oleh ketergantungan antara kondisi dan komplesitas yang dipilih (Primc \& Cater, 2015). Oleh karena itu, setiap kondisi tertentu dapat memiliki efek yang berbeda atau bahkan berlawanan, tergantung pada ada atau tidaknya kondisi tersebut.

Adanya pembelajaran sangat penting dalam meningkatkan kinerja perusahaan melalui pengaruhnya terhadap keunggulan kompetitif (Calantone, Cavusgil, \& Zhao, 2002). Dalam perusahaan besar, ukuran dan akumulasi kreatif memungkinkan mereka untuk mencapai keunggulan kompetitif baik dalam diferensiasi maupun biaya (Fernández, Iglesias-Antelo, López-López, Rodríguez-Rey, \& Fernandez-Jardon, 2019). Kinerja perusahaan besar dan kecil memiliki atribut yang istimewa dan berbeda setiap kelompoknya.

Selain itu, kinerja perusahaan juga dapat diukur menggunakan laba akuntansi atas aset dan pengembalian pasar saham tahunan atas saham biasa (Core, Holthausen, \& Larcker, 1999). Menurut hasil model agensi standar, fungsi peningkatan kinerja perusahaan yaitu dari tingkat upah karyawan yang di dapat dari laba perusahaan. Perusahaan dengan kapasitas inovatif besar, dalam hal tenaga kerja dan bakat teknis, muwujudkan tingkat pertumbuhan laba bersih dan margin laba yang lebih tinggi (Burrus, Graham, \& Jones, 2018). Hal tersebut dikarenakan kapasitas yang inovatif dalam perusahaan memberikan kontribusi terhadap kinerja perusahaan.

Tata kelola yang tidak efektif dan modal intelektual yang lemah merupakan penyakit yang dapat mempengaruhi kinerja perusahaan (Nkundabanyanga, 2016). Serta dewan perusahaan harus memantau pekerja yang dilakukan setiap harinya agar mengetahui secara langsung bagaimana kinerja perusahaan dan mengadakan rapat yang bertujuan untuk membahas hal 
penting guna meningkatkan kinerja perusahaan (Vafeas, 1999). Penganti dewan perusahaan yaitu manajer dimana seorang manajer harus memiliki pengetahuan antara tingkat diversifikasi dan kinerja perusahaan dan harus mengetahui bahwa kedua variabel tersebut saling mempengaruhi secara bersamaan (Bhatia \& Thakur, 2018). Tidak hanya itu, keragaman gender juga berpengaruh terhadap kinerja perusahaan. Sehingga, sebaiknya perusahaan memiliki lebih banyak direktur perempuan daripada CEO/GM perempuan (Solakoglu \& Demir, 2016). Penelitian memberikan bukti bahwa wanita menambahkan perspekstif baru pada strategi perusahaan untuk meningkatkan kinerja perusahaan.

Adanya manajemen small and medium-sized enterprises (SME) dapat meningkatkan kinerja perusahaan dengan berinvestasi dalam pengembangan kemampuan product management (PM) eksternal dan internal (Roach, 2011). Namun, perusahaan mencapai kinerja yang lebih rendah ketika mereka dihadapkan dengan product market competition (PMC) yang lebih tinggi (Liu, Qu, \& Hanam, 2018). Hal tersebut dikarenakan tata kelola perusahaan yang baik dapat memoderasi efek negatif PMC yang lebih tinggi pada kinerja perusahaan.

Hubungan antara exploitative technological diversification (ETD) dan kinerja perusahaam menunjukkan ada tingkat optimal ETD (Pan, Chen, \& Ning, 2018). Tingkat optimal ini tergantung pada lingkungan eksternal di mana perusahaan beroperasi. Namun dalam lingkungan kelembagaan, tidak mendukung inovasi karena menghambat kinerja perusahaan (Chadee \& Roxas, 2013). Regulasi yang buruk, penegak hukum yang lemah, dan korupsi terbukti berdampak negatif pada kapasitas inovasi dan kinerja perusahaan. Untuk itu, pengetahuan ekologi dapat diamnfaatkan. Karena, pengetahuan ekologi terbukti efektif dalam meningkatkan kemampuan IT dan kinerja perusahaan (Chen \& Liang, 2016). Perusahaan yang unggul harus berkinerja lebih baik dan lebih mudah beradaptasi dengan lingkungan yang kompetitif (Roach, 2011).

\section{EO dan Kinerja Perusahaan}

Orientasi kewirausahaan yaitu hubungan secara langsung maupun tidak langsung antara EO dengan profitabilitas perusahaan kecil (Baker \& Sinkula, 2009). Kewirausahaan merupakan salah satu kunci keberhasilan bisnis (Cho \& Lee, 2018). Keberhasilan tersebut diraih karena adanya kontribusi terhadap profitabilitas (Baker \& Sinkula, 2009). Orientasi kewirausahaan secara tidak langsung mempengaruhi kinerja perusahaan dalam menciptakan pengetahuan 
(Li, Huang, \& Tsai, 2009). Keberhasilan sebuah perusahaan membutuhkan pengetahuan tentang kewirausahaan yang lebih untuk mencapai kinerja perusahaan yang unggul (Rezaei \& Ortt, 2018). Dengan demikian, proses menciptakan pengetahuan memainkan peranan penting dalam mediasi dimana orientasi kewirausahaan bermanfaat bagi kinerja perusahaan.

Kekuatan menejerial dan orientasi kewirausahaan sangat penting untuk mengembangkan kinerja sebuah perusahaan (Davis, Bell, Payne, \& Kreiser, 2010). Hal tersebut dikarenakan kekuatan manajerial merupakan komponen penting dalam menentukan keberhasilan orientasi kewirausahaan. Terdapat efek yang berbeda pada fungsi perusahaan yang dapat membentuk nilai internal untuk menentukan kinerja perusahaan (Rezaei \& Ortt, 2018). Untuk mencapai kinerja yang unggul, perusahaan perlu menerapkan orientasi kewirausahaan melalui kapabilitas pemasaran (Sok, Snell, Lee, \& Sok, 2017). Selain itu perusahaan juga mencapai pertumbuhan unggul dari kemampuan perusahaan dalam menyelaraskan strategi operasionalnya (Shirokova, Bogatyreva, Beliaeva, \& Puffer, 2016). Oleh karena itu, orientasi kewirausahaan membutuhkan wawasan akan kewirausahaan untuk keberhasilan perusahaan (Rezaei \& Ortt, 2018).

Orientasi kewirausahaan merupakan titik awal bagi perusahaan untuk mengahasilkan kinerja yang unggul (Sok, Snell, Lee, \& Sok, 2017). Perusahaan yang dibentuk dengan adanya orientasi kewirausahaan di dalamnya dapat meningkatkan kinerja perussahaan (Cowden, Tang, \& Bendickson, 2016). Hal tersebut dilakukan melalui struktur, proses dan identitas perusahaan, akan lebih cocok untuk mempertahankan orientasi kewirausahaan dari waktu ke waktu. Efek orientasi kewirausahaan dan hasrat untuk bekerja pada kinerja perusahaan semakin dimoderasi oleh lingkungan (Adomako, Quartey, \& Narteh, 2016). Selain itu, hubungan antara orientasi kewirausahaan dan kinerja perusahaan berbeda dengan kombinasi karakteristik lingkungan dan pendekatan konfigurasi (Shirokova, Bogatyreva, Beliaeva, \& Puffer, 2016).

Perusahaan harus menyeimbangkan semangat orientasi kewirausahaan dan manajer untuk bekerja dalam lingkungan pasar yang terus berubah (Adomako, Quartey, \& Narteh, 2016). Pendekatan manajemen kualitas, penilaian dirin dan benchmarking dapat dilakukan oleh manajer untuk meningkatkan kinerja perusahaan yang lebih tinggi (Sahoo \& Yadav, 2017). Selain itu, daya tarik tujuan dan orientasi kewirausahaan merupakan faktor penentu baik atau buruknya kinerja perusahaan (Fadda \& Sorensen, 2017). Orientasi kewirausahaan dapat 
bermanfaat terhadap kinerja perusahaan (Kajalo \& Lindblom, 2015). Karena orientasi kewirausahaan berfungsi sebagai pendorong dalam meningkatkan kinerja perusahaan. Orientasi kewirausahaan memiliki dampak pada kinerja perusahaan di pasar negara berkembang (Gruber-Muecke \& Hofer, 2015).

Agresivitas dan proaktif merupakan dimensi orientasi kewirausahaan. Kedua dimensi tersebut memberikan kontribusi baik untuk kinerja perusahaan (Lumpkin \& Dess, 2001). Terlihat bahwa, orientasi kewirausahaan memiliki dampak positif terhadap kinerja perusahaan (Davis, Bell, Payne, \& Kreiser, 2010). Selain itu, pengambilan risiko juga berpengaruh terhadap kinerja ketika perusahaan dalam keadaan turbulensi teknologi informasi (Pratono, 2018). Sementara itu, orientasi kewirausahaan penting untuk keberhasilan perusahaan saat ini (Davis, Bell, Payne, \& Kreiser, 2010).

\section{Risiko Dalam Mengadopsi Teknologi Bersih}

Perilaku pengambilan risiko menyebabkan hubungan antra kompetensi manajerial dan keuangan melemah (Nkundabanyanga, Opiso, Balunyawa, \& Nkote, 2015). Di lain pihak, ada keraguan tentang peranan pendidikan formal. Ada sebuah studi empiris yang mengatakan bahwa pendidikan kewirausahaan tidak berpengaruh terhadap orientasi kewirausahaan (Cho \& Lee, 2018). Pengambilan risiko sangat penting dalam tahap awal memulai bisnis (Kropp, Lindsay, \& Shoham, 2008). Risiko merupakan kehilangan, kerugian, atau kehancuran (Ratliff \& Hanks, 1992). Sedangkan pengambilan risiko itu sendiri adalah kemampuan individu atau organisasi dalam mengambil keputusan yang berisiko yang memiliki dampak pada keberhasilan atau kegagalan (Ratliff \& Hanks, 1992). Dalam literatur lainnya, pengambilan risiko terjadi ketika perusahaan menetapkan pilihan dalam keadaan turbulensi teknologi informasi (Pratono, 2018).

Wirausahawan yang sukses yaitu wirausahawan yang menjaga citra perusahaan sehingga dapat meringankan pengambilan risiko. Keluarga dapat berfungsi sebagai aset dan kekuatan bagi perusahaan itu sendiri (Memili, Eddleston, Kellermanns, Zellwegar, \& Barnett, 2010). Wirausahawan harus mengenali dan memahami terlebih dahulu lingkungan sekitar. Hal tersebut diakrenakan, interaksi sosial berperan dalam keputusan pengambilan risiko sehingga wirausahawan harus menyesuaikan diri dengan lingkungan serta dalam memilih rekan kerja (Lopera \& Marchand, 2018). Kekayaan awal dapat menurunkan pengambilan risiko, sedangkan pengambilan risiko itu sendiri akan meningkat apabila terjadi ketidaksetaraan 
imbalan dalam perusahaan (Hopkins, 2018). Tidak hanya itu, pengurangan tarif pajak pribadi dapat secara substansial mengurangi pengambilan risiko perusahaan (Cullen \& Gordon, 2007). Pemotongan pajak seperti itu dapat mengurangi pajak yang disimpan dari pengurangan kerugia bisnis, sementara laba seringkali tetap dikenakan pajak pada tarif pajak perusahaan. Akibatnya pengambilan risiko tidak dianjurkan.

\section{Teknologi Bersih dan Kinerja Perusahaan}

Inovasi dengan teknologi bersih dipercaya dapat meningkatkan kinerja perusahaan yang lebih unggul terbukti dari keberhasilannya mengembangkan teknologi lebih lanjut (Alhola \& Nissinen, 2018). Pendapat tersebut juga disetujui oleh beberapa literatur lainnya yang berargumen bahwa untuk menciptakan perusahaan yang menjanjikan di masa depan, maka perusahaan harus mengadopsi inovasi dengan clean technology (Benchekroun \& Chaudhuri, 2014). Bagi perusahaan yang menerapkan inovasi dengan clean technology maka akan meningkatkan kinerja dalam sebuah perusahaan (Erzurumlu \& Erzurumlu, 2013). Dalam sebuah literatur lainnya juga mengatakan bahwa China telah menerapkan inovasi dengan clean technology yang terbukti dapat mengembangkan kinerja perusahaan terlebih lagi perusahaan tersebut berfokus pada inovasi dengan clean technology (Tan, 2010).

Bagi perusahaan kecil, inovasi bisa dilakukan dengan berjejaring, sehingga mempunyai akses untuk mengadopsi inovasi yang dikembangkan organisasi lain (Pratono, 2018). Manajer dengan tingkat orientasi kewirausahaan yang tinggi cenderung menerapkan teknologi untuk memberikan kinerja yang lebih besar daripada manajer dengan tingkat orientasi kewirausahaan yang rendah (Abebe, 2014). Selain itu, kekuatan prestise juga merupakan karakteristik penting yang harus ditekankan oleh manajer puncak dalam perusahaan (Davis, Bell, Payne, \& Kreiser, 2010). Berdasarkan literatur ini juga mengatakan bawah inovasi dengan clean technology dapat menciptakan kinerja perusahaan yang baik terutama dalam menghadapi tantangan yang besar kedepannya (Gorissen, Manshoven, \& Vrancken, 2014).

Upaya mengadopsi inovasi yang ramah lingkungan tentunya bukan hanya masalah keuntungan, namun juga kemampuan mengelola sumber daya yang terbatas maupun kemampuan berkolaborasi dalam rantai pasok global (Pratono, 2019). Oleh karena itu, perusahaan harus merubah sistem dengan menggunakan inovasi dengan clean technology agar kinerja sebuah perusahaan dapat menciptakan ekonomi yang baik (Fortune, 2019). Inovasi dengan clean technology itu harus terus dikembangkan dalam perusahaan agar 
kinerja perusahaan menjadi lebih baik, efektif dan menjanjikan untuk kedepannya (MacNeil, Koch, Kuspinar, Juzwishin, Lehoux, \& Stolee, 2019). Dalam literatur lainnya juga mengatakan penerapan inovasi dengan clean technology sangat penting dalam pengembangan kinerja sebuah perusahaan (Wicki \& Hansen, 2017).

Untuk meningkatkan kinerja perusahaan, perusahaan harus menerapkan inovasi dengan clean technology karena inovasi dengan clean technology menjadi sumber yang efisien bagi perusahaan (Hassani, Silva, \& Al Kaabi, 2017). Begutu pula menurut literatur lainnya yaitu inovasi dengan clean technology yang diterapkan oleh perusahaan akan menciptakan kinerja yang lebih optimal dibandingkan dengan perusahaan yang tidak menerapkannya (Sovacool, et al., 2017). Namun dalam literatur ini membantah akan inovasi dengan clean technology dapat menyeabkan kinerja perusahaan menjadi lebih baik. Dalam literatur ini menyatakan babhwa perusahaan yang menerapkan inovasi dengan clean technology akan menjadikan perusahaan tidak baik untuk kedepannya (Du, Li, Guo, \& Tang, 2019).

Pergeseran strategi pembelajaran dari dari pengembangan kegiatan bisnis perlu diarahkan pada pada kemampuan suatu organisasi melalui peningkatan fokus karyawan, dan kemampuan eksploratif (Cheng \& Shiu, 2015). Strategi lainnya berupa penggunaan teknologi E-Commerce, dimana penggunaan teknologi E-Commerce sangat berpengaruh terhadap penjualan perusahaan. Dalam sebuah literatur mengatakan tingkat penjualan jauh lebih tinggi dengan menggunakan teknologi E-Commerce dibandingkan dengan tidak menggunakan teknologi E-Commerce (Abebe, 2014). Tentunya alokasi sumber daya berbasis teknologi tersebut bukan hanya menjanjikan kinerja perusahaan yang lebih baik tetapi juga mengandung risiko.

\section{Bibliography}

Abebe, M. (2014). Electronic commerce adoption, entrepreneurial orientation and small-and medium-sized enterprise (SME) performance. Journal of Small Business and Enterprise , 21 (1), 100-116.

Adomako, S., Quartey, S. H., \& Narteh, B. (2016). Entrepreneurial orientation, passion for work, perceived environmental dynamism and firm performance in an emerging economy. Journal of Small Business and Enterprise Development , 23 (3), 728-752. 
Alhola, K., \& Nissinen, A. (2018). Integrating cleantech into innovative public procurement process - evidence and success factors. Journal of Public Procurement , 18 (4), 336354.

Altinay, L., \& Wang, C. L. (2011). The influence of an entrepreneur's socio-cultural characteristics on the entrepreneurial orientation of small firms. Journal of Small Business and Enterprise Development , 18 (4), 673-694.

Awwad, M. S., \& Ali, H. K. (2012). Emotional intelligence and entrepreneurial orientation: The moderating role of organizational climate and employees creativity. Journal of Research in Marketing and Entrepreneurship , 14 (1), 115-136.

Aydemir, S. D., \& Aren, S. (2017). Do the effects of individual factors on financial risktaking behavior diversify with financial literacy? Kybernetes , 46 (10), 1706-1734.

Baker, W. E., \& Sinkula, J. M. (2009). The complementary effects of market orientation and entrepreneurial orientation on profitability in small businesses. Journal of Small Business Management , 47 (4), 443-464.

Benchekroun, H., \& Chaudhuri, A. R. (2014). Transboundary pollution and clean technologies. Resource and Energy Economics , 36 (2), 601-619.

Bhatia, A., \& Thakur, A. (2018). Corporate diversification and firm performance: An empirical investigation of causality. International Journal of Organizational Analysis , 26 (2), 202-225.

Burrus, R. T., Graham, E., \& Jones, A. T. (2018). Regioal innovation and firm performance. Journal of Business Research , 88, 357-362.

Calantone, R. J., Cavusgil, S. T., \& Zhao, Y. (2002). Learning orientation, firm innovation capability, and firm performance. Industrial Marketing Management , 31 (6), 515524.

Chadee, D., \& Roxas, B. (2013). Institutional environment, innovation capacity and firm performance in russia. Critical perspectives on international business , 9 (1/2), 1939.

Chen, D.-N., \& Liang, T.-P. (2016). Knowledge diversity and firm performance: An ecological view. Journal of Knowledge Management , 20 (4), 671-686.

Cheng, C. C., \& Shiu, E. C. (2015). The inconvenient truth of the relationship between open innovation activities and innovation performance. Management Decision , 53 (3), 625-647. 
Cho, Y. H., \& Lee, J.-H. (2018). Entrepreneurial orientation, entrepreneurial education and performance. Asia Pasific Journal of Innovation and Entrepreneurship , 12 (2), 124134.

Core, J. E., Holthausen, R. W., \& Larcker, D. F. (1999). Corporate governance, chief executive officer compensation, and firm performance. Journal of Financial Economics , 51 (3), 371-406.

Cowden, B. J., Tang, J., \& Bendickson, J. (2016). The maturity of entrepreneurial firms: Entrepreneurial orientation, firm performance, and administrative heritage. New England Journal of Entrepreneurship , 19 (2), 42-53.

Cullen, J. B., \& Gordon, R. H. (2007). Taxes and entrepreneurial risk-taking: Theory and evidence for the U.S. Journal of Public Economics , 91 (7-8), 1479-1505.

Davis, J. L., Bell, R. G., Payne, G. T., \& Kreiser, P. M. (2010). Entrepreneurial orientation and firm performance: The moderating role of managerial power. American Journal of Business , 25 (2), 41-54.

Du, J., Li, P., Guo, Q., \& Tang, X. (2019). Measuring the knowledge translation and convergence in pharmaceutical innovation by funding-science-technologyinnovation linkages analysis. Journal of informetrics , 13 (1), 132-148.

Erzurumlu, S. S., \& Erzurumlu, Y. O. (2013). Development and deployment drivers of clean technology innovations. The Journal of High Technology Management Research , 24 (2), 100-108.

Fadda, N., \& Sorensen, J. F. (2017). The importance of destination attractiveness and entrepreneurial orientation in explaning firm performance in the sardinian accommodation sector. International Journal of Contemporary Hospitality Management, 29 (6), 1684-1702.

Fernández, E., Iglesias-Antelo, S., López-López, V., Rodríguez-Rey, M., \& FernandezJardon, C. M. (2019). Firm and industry effects on small, medium-sized and large firms' performance. BRQ Business Research Quarterly , 22 (1), 25-35.

Fortune, G. (2019). The impact of innovation and technology investments on carbon emissions in selected organisation for economic co-operation and development countries. Journal of Cleaner Production, 217, 469-483.

Gorissen, L., Manshoven, S., \& Vrancken, K. (2014). Tailoring business model innovation towards grand challenges: Employment of a transition management approach for the social enterprise "re-use centers". Journal of Global Responsibility , 5 (2), 289-311. 
Gruber-Muecke, T., \& Hofer, K. M. (2015). Market orientation, entrepreneurial orientation and performance in emerging markets. International Journal of Emerging Markets , $10(3), 560-571$.

Hassani, H., Silva, E. S., \& Al Kaabi, A. M. (2017). The role of innovation and technology in sustaining the petroleum and petrochemical industry. Technological Forecasting and Social Change, 119, 1-17.

Hopkins, E. (2018). Inequality and risk-taking behaviour. Games and Economic Behavior, $107,316-328$.

Kajalo, S., \& Lindblom, A. (2015). Market orientation, entrepreneurial orientation and business performance amon small retailers. International Journal of Retail \& Distribution Management , 43 (7), 580-596.

Kropp, F., Lindsay, N. J., \& Shoham, A. (2008). Entrepreneurial orientation and international entrepreneurial business venture startup. International Journal of Entrepreneurial Behavior \& Research , 14 (2), 102-117.

Li, Y.-H., Huang, J.-W., \& Tsai, M.-T. (2009). Entrepreneurial orientation and firm performance: The role of knowledge creation process. Industrial Marketing Management, 38 (4), 440-449.

Liu, L., Qu, W., \& Hanam, J. (2018). Product market competition, state-ownership, corporate governance and firm performance. Asian Review of Accounting , 26 (1), 62-83.

Lopera, M. A., \& Marchand, S. (2018). Peer effects and risk-taking among entrepreneurs: Lab-in-the-field evidence. Journal of Economic Behavior \& Organization , 150, 182201.

Lumpkin, G. T., \& Dess, G. G. (2001). Linking two dimensions of entrepreneurial orientation to firm performance: The moderating role of environment and industry life cycle. Journal of Business Venturing , 16 (5), 429-451.

MacNeil, M., Koch, M., Kuspinar, A., Juzwishin, D., Lehoux, P., \& Stolee, P. (2019). Enabling health technology innovation in Canada: Barriers and facilitators in policy and regulatory processes. Health Policy, 123 (2), 203-214.

McCarthy, B. (2000). The cult of risk taking and social learning: A study of irish entrepreneurs. Management Decision , 38 (8), 563-575.

Memili, E., Eddleston, K. A., Kellermanns, F. W., Zellwegar, T. M., \& Barnett, T. (2010). The critical path to family firm success through entrepreneurial risk taking and image. Journal of Family Business Strategy , 1 (4), 200-209. 
Moschilla, J. A., Tomkins, J. L., \& Simmons, L. W. (2018). Stet-dependent changes in risktaking behaviour as a result of age and residual reproductive value. Animal Behaviour, 142, 95-100.

Nkundabanyanga, S. K. (2016). Board governance, intellectual capital and firm performance: Importance of multiplicative effects. Journal of Economic and Administrative , 32 (1), 20-45.

Nkundabanyanga, S. K., Opiso, J., Balunyawa, W., \& Nkote, I. N. (2015). Financial sercice outreach correlates: Managerial competence and risk-taking behaviour. International Journal of Social Economics , 42 (4), 404-420.

Pan, X., Chen, X., \& Ning, L. (2018). Exploitative technological diversification, environmental contexts, and firm performance. Management Decision , 56 (7), 16131629.

Pratono, A. H. (2019). Cross-cultural collaboration for inclusive global value chain: a case study of rattan industry. International Journal of Emerging Markets, https://www.emeraldinsight.com/doi/full/10.1108/IJOEM-01-2017-0028.

Pratono, A. H. (2018). Does firm performance increase with risk-taking behavior under information technological turbulence?: Empirical evidence from Indonesia SMEs. The Journal of Risk Finance , 19 (4), 361-378.

Pratono, A. H. (2018). Network structure and open innovation: the role of trust in product development. International Journal of Business Innovation and Research , 15 (1), 44-61.

Pratono, A. H., Darmasetiawan, N. K., Yudiarso, A., \& Jeong, B. G. (2019). Achieving sustainable competitive advantage through green entrepreneurial orientation and market orientation: The role of inter-organizational learning. The Bottom Line , 32 (1), 2-15.

Primc, K., \& Cater, T. (2015). Environmental proactivity and firm performance: A fuzzy-set analysis. Management Decision , 53 (3), 648-667.

Ratliff, R., \& Hanks, S. (1992). Evaluating Risk. Managerial Auditing Journal , 7 (5), 26-32.

Rezaei, J., \& Ortt, R. (2018). Entrepreneurial orientation and firm performance: The mediating role of functional performances. Management Research Review , 41 (7), 878-900.

Roach, D. C. (2011). The impact of product management on SME firm performance. Journal of Research in Marketing and Entrepreneurship , 13 (1), 85-104. 
Sahoo, S., \& Yadav, S. (2017). Entrepreneurial orientation of SMEs, total quality management and firm performance. Journal of Manufacturing Technology Management , 28 (7), 892-912.

Shirokova, G., Bogatyreva, K., Beliaeva, T., \& Puffer, S. (2016). Entrepreneurial orientation and firm performance in different environmental settings: Contingency and configurational approaches. Journal of Small Business and Enterprise Development , $23(3), 703-727$.

Sok, P., Snell, L., Lee, W. J., \& Sok, K. M. (2017). Linking entrepreneurial orientation and small service firm performance through marketing resources and marketing capability: A moderated mediation model. Journal of Service Theory and Practice, $27(1), 231-249$.

Solakoglu, M. N., \& Demir, N. (2016). The role of firm characteristics on the relationship between gender diversity and firm performance. Management Decision , 54 (6), 1407-1419.

Sovacool, B. K., Jeppesen, J., Bandsholm, J., Asmussen, J., Balachandran, R., Vestergaard, S., et al. (2017). Navigating the "paradox of openness" in energy and transport innovation: Insights from eight corporate clean technology research and development case studies. Energy Policy, 105, 236-245.

Tan, X. (2010). Clean technology R\&D and innovation in emerging countries-Experience from China. Energy Policy, 38 (6), 2916-2926.

Vafeas, N. (1999). Board meeting frequency and firm performance. Journal of Financial Economics , 53 (1), 113-142.

Wicki, S., \& Hansen, E. G. (2017). Clean energy storage technology in the making: An innovation systems perspective on flywheel energy storage. Journal of Cleaner Production , 162, 1118-1134. 